OmniaScience

Journal of Technology and Science Education

JOTSE, 2017 - 7(1): 26-57 - Online ISSN: 2013-6374 - Print ISSN: 2014-5349

https://doi.org/10.3926/jotse.234

\title{
USING TECHNOLOGY TO SUPPORT SCIENCE INQUIRY LEARNING
}

\author{
P John Williams ${ }^{1}$ D, Nhung Nguyen ${ }^{2}$, Jenny Mangan $^{3}$ (iD \\ ${ }^{1}$ Science and Maths Education Centre, Curtin University, Perth (Australia) \\ ${ }^{2}$ Open Polytechnic, Wellington (New Zealand) \\ ${ }^{3}$ Technology Environmental, Mathematics and Science Education Research Centre, \\ The University of Waikato, Hamilton (New Zealand) \\ pjohn.williams@.curtin.edu.au, hnn3@students.waikato.ac.nz, jenny.mangan25@gmail.com
}

Received June 2016

Accepted January 2017

\section{Abstract}

This paper presents a case study of a teacher's experience in implementing an inquiry approach to his teaching over a period of two years with two different classes. His focus was on using a range of information technologies to support student inquiry learning. Data was collected over the two year period by observation, interview and student work analysis. The study demonstrates the need to consider the characteristics of students when implementing an inquiry approach, and also the influence of the teachers level of understanding and related confidence in such an approach. The case also indicated that a range of information and communication technologies can be effective in supporting student inquiry learning.

Keywords - Science inquiry, Information technology, Inquiry pedagogy. 


\section{Introduction}

Declining interest and participation of young people in school science and subsequent sciencerelated careers is causing increasing concern due to the impact this may have on our future workforce and general levels of scientific literacy. A change in pedagogy towards an inquirybased approach is considered a critical factor in addressing this problem of disengagement in science. This is reflected in recent education reforms that emphasise the importance of understanding the nature of science and implementing inquiry-based approaches to teaching and learning (Bolstad \& Hipkins, 2008; National Research Council, 2000; Tytler, Osborne, Williams, Tytler \& Cripps Clark, 2008).

Science inquiry refers to the processes scientists use to pose questions about the natural world, investigate phenomena and acquire scientific knowledge (Crawford, 2007; Schwartz, Lederman, \& Crawford, 2004). Inquiry learning in science is the engagement of students in the kinds of cognitive processes that scientists use such as asking questions, generating hypotheses, designing investigations, collecting and analysing data to resolve the question, and communicating and justifying explanations (Crawford, 2000; Lee, Linn, Varma \& Liu, 2010; National Research Council, 2000; Windschitl, 2003). The aim of inquiry learning is for students to develop abilities to do scientific inquiry, to gain understandings about scientific inquiry and the nature of science, and also to develop deep understandings of scientific concepts and principles through scientific inquiry (Crawford, 2007; National Research Council, 2000).

Research indicates that inquiry learning has potential to increase student engagement, interest and motivation in science (Hong, Hwang, Lui, Ho \& Chen, 2014). Gengarelly and Abrams (2008) suggest that inquiry-based learning is essential for students to develop scientific literacy. They claim that it supports improved student understanding of science concepts, and that engaging in the process of doing science improves students' understanding of the nature of science, teaches them how to question things and formulate their own explanations, and improves students' attitudes towards science.

To develop understanding of the nature of scientific inquiry it is important that students engage in authentic science problems that are solved collaboratively (Crawford, 2000). These types of activities are quite different from more conventional teaching approaches and implementation is deemed complex (Windschitl, 2003; Haug, 2014). As a result, it has not been embraced by many teachers and a range of views and instructional approaches exist (Crawford, 2000, 2007). Research suggests that inquiry learning is often confused with hands-on activities and 
"experiments", sometimes referred to as "cookbook" activities, that focus on finding the "right" answer and are often unconnected to substantive science content (Crawford, 2000; Gengarelly \& Abrams, 2008; National Research Council, 2000). These activities tend to focus on procedures rather than analysis and understanding, and are often not integrated with other classroom activities. Similar criticism is aimed at representations of inquiry as a linear process, which leads to misconceptions of a universal scientific method (Crawford, 2000; Windschitl, 2003).

Researchers have identified various approaches or levels of inquiry in classrooms (Bell, Smetana, \& Binns, 2005; Crawford, 2007; Windschitl, 2003). These range from "confirmation" experiences at the lowest level (where students verify known scientific principles following a given procedure), to structured inquiry (teachers provide the question and the procedure to follow), "guided" inquiry (teachers provide the problem but students decide on methods to resolve the problem), and finally "open" inquiry (students develop their own questions and methods of investigation). Each level is significantly more intellectually challenging for the learner and pedagogically complex for teachers than the level below, and the lower levels are substantially more teacherdirected (Gengarelly \& Abrams, 2008). Bell et al. (2005) argue that this inquiry scale should be viewed as a continuum and that students should progress gradually to the higher level, supported by appropriate teacher scaffolding at each level.

Successful inquiry learning demands a significant shift from a more traditional pedagogy and a corresponding change in teachers' and students' roles in the classroom. Teaching becomes more interactive and student-centred, involving collaboration and co-construction of knowledge through engagement in problem-based activities in authentic and relevant contexts. The potential of web-based technologies to support the more interactive and collaborative pedagogies required for effective inquiry-based learning is well documented (Bolstad, Gilbert, McDowall, Bull, Boyd \& Hipkins, 2012; Erstad, 2005; Voogt, Erstad, Dede \& Mishra, 2013; Wright, 2010).

Particular affordances that web-based technologies offer to support inquiry learning include quick and flexible access to information, resources and experts (Wright, 2010). Opening up more variety of resources and making the outside world accessible provides opportunity for students to pursue questions that are of interest and relevance to them (Erstad, 2005; Wallace, Kupperman, Krajcik \& Soloway, 2000). In addition, the multimodal nature of resources and ways of communicating ideas has potential to enrich outcomes and provide support for differentiation to meet varying student abilities and preferred ways of working (Erstad, 2005). A wide range of web-based technologies support sharing, co-construction and communication of ideas among 
students, teachers and community experts both within and beyond the classroom. Such technologies have potential to encourage greater student ownership of their learning and to enrich their developing understandings (Williams, Cowie, Khoo, Saunders, Taylor \& Otrel-Cass, 2013). The potential to involve the outside community and an authentic audience also provides motivation and encourages higher quality and more authentic student work (Erstad, 2005). Students are able to become knowledge producers rather than only consumers (Erstad, 2005; Wright, 2010).

Although some research indicates that use of technology may influence collaborative interactive pedagogies and change the dynamics of the classroom when it is used regularly (Cowie et al., 2007; Erstad, 2005; Wright, 2010), it is clear that effective technology-supported learning does not happen without deliberate pedagogical actions of the teacher (Hoffman, Wu, Krajcik, \& Soloway, 2003; Wright, 2010). The teachers' role in scaffolding learning with or without technology remains critical to create the collaborative, student-centred and knowledge-building learning environments characteristic of authentic and successful inquiry-based approaches (Ministry of Education, 2006; Wright, 2010).

Successful inquiry teaching is complex and a range of interacting factors impact on its success including student, teacher, and school factors (Lee et al., 2010). Using technology effectively to support learning presents similar challenges. Both have potential to make learning more relevant and engaging and to develop the skills considered essential for learners in the 21 st century, when supported by effective pedagogy and appropriate scaffolding. However, as outlined above, neither happen automatically and both are dependent on the teacher effecting considerable change in their pedagogy and their role in the classroom. Research suggests that teacher beliefs may be the most critical factor influencing their intentions and abilities to teach science as inquiry and that they need time and support to develop their skills and beliefs to enable the pedagogical shift required (Crawford, 2007; Lee et al., 2010; Tseng, Tuan \& Chin, 2012; Wallace \& Kang, 2004). It is also suggested that constraints imposed by school culture such as expectations of students, time pressure to cover the curriculum and preparation for assessment may challenge teachers' developing beliefs about inquiry learning and create barriers to implementing inquiry (Crawford, 2007; Wallace \& Kang, 2004).

This study reported here aimed to address these issues raised by research and to build on and contribute understandings of how information technology-supported science inquiry helps to enhance the teaching and learning of science in school. The case that is reported here examines 
one teacher's experience of implementing technology-supported inquiry learning in science over a period of two years. This will assist in developing understanding and closing the literature gaps related to teacher beliefs and student perceptions. This case was chosen on the basis of the teacher's willingness to develop his inquiry experience and to be involved in the research, and the proximity of the case to the researchers university location.

\section{Methods}

This article is based on the findings from a two year Teaching and Learning Research Initiative (TLRI) funded case study: 'Networked Inquiry Learning in Secondary Science' (NILSS). The aim of the study was to explore the nature of science inquiry in the development of knowledge supported through technology (Williams et al., 2013). The research questions which guided the study were:

- What are the teachers ideas, experiences and visions about supporting inquiry learning in science with technology?

- How do understandings change as students collaboratively engage in inquiry learning projects?

The intent of these questions was to achieve the following research objectives:

- Describe the development of teacher understandings from a naive to informed position related to inquiry teaching in science;

- Indicate how a range of technologies can be used in science inquiry to achieve the desired outcomes;

- Analyse the level and type of support needed by students involved in an inquiry approach to learning science.

- Indicate how technologies can be used to expand inquiry activities beyond the classroom.

This study built on other studies into assessment, culturally responsive pedagogy and the contribution of Information and Communication Technologies (ICT) in science classrooms (Cowie, Moreland \& Otrel-Cass, 2013; Otrel-Cass, Cowie \& Khoo, 2011). The case study was with a science teacher of year nine and ten students, with an average age of 13 and 14 years in a New Zealand high school. The teacher and researchers spent time together in the early planning 
workshops developing a shared understanding of inquiry, and how this could be enacted. Literature around the nature of Inquiry was presented, exemplars were discussed, and the teacher contributed his ideas, though he had no prior experience with the implementation of inquiry learning; his understanding was developed through the workshops and continued to develop through interactions with his colleagues and the researchers. Previous research indicates that both a vision for learning, drawn from the constructivism inherent in thinkers like Piaget, and the necessary science content are important prerequisites to supporting student investigations (Feldman, Konold, Coulter, Conroy, Hutchison, \& London, 2000).

The researchers observed the inquiry projects in the classroom and then, together with the teacher, reviewed and analysed the data that had been collected during the observations. Data produced and collected by the teacher and researchers throughout the project included:

- teacher planning documents;

- classroom observation (field notes, photographs and audio and video recordings);

- student work (homework, presentations, websites, movies, posters and email conversations;

- online records from networked activities (e.g., blogs); and,

- formal and informal interviews with teacher and students.

This range of sources of data was selected in order to answer the research questions and capture the evolving ideas of the teacher and students, and their engagement with the inquiry process and with the technologies used. The data provided rich detailed descriptions of how the process of using e-networked tools to support inquiry in science evolved. An interpretative research paradigm was used to search for common themes (Merriam, 2002). The first level of data analysis included initial reflections by and with the teacher, students and researchers after the classroom observations which were shared by researchers online using Google Groups, ensuring records could be tracked and aided in preserving the credibility of the project (Guba \& Lincoln, 1994). The notes on Google Groups were analysed for themes and accordingly video sequences were selected from the classroom observations for the second level of analysis using the Nvivo software package. The final level of analysis involving the integration of transcripts, reports and interview data further supported the analyses. 
In this case a range of technologies were used in the class, and the teachers conceptions of inquiry evolved from naïve ideas and no experience initially, to a more sophisticated conception by the end of the second year. In the first year of the project he taught a class that had limited knowledge and skills while the class taught in the second year was at a more advanced level. Over these two years he adopted a range of approaches, as his own confidence and experience developed, and as he adapted his pedagogy to the student's different interests, experience, attitude and ability.

Over the two year period, this teacher taught science in a regular classroom, which was equipped with a data projector. The classes were mixed gender, with about 25 students in each class. The teacher had access to some flip cameras, and a trolley of laptop computers could be booked for the class.

\section{Findings}

In the first two findings sections, the range of the inquiry learning activities that were organised in each year will be described in order to provide the context for the supportive application of information technology to specific inquiry tasks. The description of these inquiry activities is based on the analysis of researcher observation notes, teacher journals, photos and audio recordings of the science classes.

The technology-supported inquiry learning experiences will be then examined from the students' and the teacher's perspective in section 3.3 and 3.4. This section presents the students' reflection on their technology use and the inquiry activities that they conducted, and the next section discusses the teacher's thinking that underpinned the inquiry activities and classroom organization. An analysis of how the teacher scaffolded his students when they used technology to support inquiry learning, and his reflections of his learning journey throughout the two years of this project conclude the section. 


\subsection{Inquiry activities in the first year}

For this class, the teacher involved in the research project continued with some of the activities he had planned prior to the introduction of an inquiry approach, and some of the activities were new. This led to a sequence of activities which could have been more logically devised had inquiry been a focus at the planning stage.

In the first year the class participating in the research was in Year 10, and as the teacher identified, the students' background knowledge and abilities were initially limited:

The class were low in knowledge and ability, and also in interest initially, but by using everyday elements and themes the students were soon quick to buy in and were able to relate back to their own experiences. That made it real and relevant.

\subsubsection{Inquiry Activity 1: "What do scientists do?"}

In an attempt to establish an introduction and rationale for the students' approaches to inquiry learning, the teacher began the inquiry task with the question "Who are scientists and what do they do?"

After some initial discussion the teacher then showed a presentation of famous scientists and asked students the names of the scientists as well as what they do. When he showed the pictures, a number of students tried to identify the scientists. A lot of scaffolding and encouragement was required in this activity, as the research observer commented:

Some [students] were quite off track, with their answers but he [the teacher] commended them for having a go. It was quite evident from an early part of the lesson the students in this group were of a medium to low ability. $D$ [the teacher] encouraged his students with lots of praise and reinforcing comments... Most students were keen to have a go.

While the teacher encouraged the students to discuss and answer the questions, he concurrently provided them with information about the scientists.

The students were then provided with a brainstorming sheet on which they worked in groups and tried to brainstorm the argument for whether 'an amateur gardener growing prized affodils is being a scientist. Under the guidance of the teacher, the groups brainstormed and discussed what a 
scientist does and how that related to their discussion question. After filling in the brainstorming sheets, each group explained their logic to the class by writing their arguments on the board.

With the support of the teacher, the students then attempted to relate the work of a scientist to examples they knew and were familiar with. They also discussed what science is. At the end of the discussion, the teacher supported the students' work by reading a small extract about the nature of science. The observer remarked that the teacher's reading “... was a nice summary activity that was at a level the students could understand. It also probed discussion from a number of the students about science".

This activity was designed by the teacher as preparatory to the introduction of an inquiry approach. The goal was to gain an understanding of the levels at which the students were working, and to begin building a classroom climate of trusting relationships both between the students and with the teacher. "D clearly worked very hard to encourage positive thinking and strong teacherstudent relationships. There was a strong sense of good faith and humour." (research observer)

\subsubsection{Inquiry Activity 2: "Mixtures and compounds"}

From the beginning of the class, the teacher spent time scaffolding students' understanding of the language they required in order to successfully perform and comment on science tasks. He had a conversation with the whole class to help the students understand three definitions of Element, Compound and Mixture. The teacher then gave the students a practical task of separating iron, salt and sand. The task was specified as: You bave a mix of iron/salt/sand. In your groups you are to explore the processes needed to separate out each component.

There were five groups each of four students, who were provided with the following equipment: $5 \mathrm{mg}$ of the mixture, water, magnets, measuring cylinders, weighing scales, beakers, funnel, filter paper, thermometer, evaporating dish, stopwatch and bunsen burner. The groups were also asked to fill in information on a handout sheet about mass, mass of iron, volume of water, temperature of water during evaporating and time to evaporate.

At first, the students were generally confused, not knowing how to begin. Then they gradually thought through the problem and decided on a process, getting clues from the materials they were given such as the magnets. There was a significant degree of between-group communication, and eventually the five groups found out how to separate the components from the mixture, with some support from the teacher in the form of directed questioning. 
Some of the groups of students used mobile phones to take photos and record the process of conducting the experiment. The use of mobile phones in this case was the students' initiative. They said that the recordings helped them to remember, revise better and see details. The research observer commented that "The students worked like young scientists, thought through and so discovered the method of separating the elements from the mixture, and then recorded their discovery."

The goal of the teacher with this short activity was to introduce the class to some of the elements of inquiry learning such as working in groups to determine relevant processes to follow in order to achieve a goal. The teacher told the students at the beginning of this activity that he would not provide instructions, so they were aware they had to 'work it out'. They still found it frustrating, however, and the teacher regularly supported and prompted the students' thinking by asking guiding questions.

\subsubsection{Inquiry Activity 3: "Writing interview scripts for Māori TV"}

This specific inquiry activity was a part of a broader inquiry theme project: producing a short news item about the local Waikato River for Māori TV. The task of this week was that the students were going to report on the evening Māori TV news about a major environmental catastrophe which could happen in their local area. The students could choose from these scenarios:

- A fertiliser truck has crashed into a stream.

- A tank of acid wash leaked overnight and the acid has gone down the storm system into the river.

- A truck driver fills the truck with petrol instead of diesel by mistake. The driver empties the petrol down the storm water drain.

- The council drops poison baits for possums into the town water supply by accident. The water supply is polluted and no one can drink the water.

The students were to play the role of the reporter, so needed to find out all the facts of the situation. They also needed to consider interviewing people to ensure that different viewpoints were covered: the council, the perpetrator, a local bystander, a witness, a person who uses water such as a farmer for stock water, local iwi gathering kai, local white baiters, people fishing, water skiing, rowing, regional council water monitoring staff, fire brigade, etc. They were required to 
link their ideas for the report to science ideas. The teacher also reminded the students of the initial questions they worked on in the previous week, which were:

- Why water is essential to life and what are properties of water that make it so valuable?

- How does water change the surface of the earth, and does that impact the availability of water as a resource?

- What can I do to help conserve this valuable resource?

In this learning activity, the teacher asked the students to use the Internet to find information for the task. He provided the students with laptops and told them that he thought the Internet might not be accessible, but they would try. After persevering for about 15 minutes, none of the students could access the Internet. The teacher then let the students know that he had a plan B: the students were asked to work in groups to write interview scripts. The teacher reminded the students of the knowledge they had accumulated, and recommended that they speak from their heart. He also gave students the option of drawing cartoons as a way to come up with a story board to help them with their planning/thinking.

A group of three girls took the initiative to use their cell phones to access the Internet and find information, discuss it in their group, document it on the laptop, then carry out an experiment and use cell phones to film the experiment.

There was a high level of diversity across groups in the time taken to complete the task. The level of cooperation within groups was not as effective as the teacher expected, in that one or two students appeared to do the majority of the work, and the contribution of other students to the group discussion was minimal. As a result the teacher realized that some students had been inadequately scaffolded to work effectively in groups, and others were not engaged with the learning activity. One group used their computer to play games throughout the class period. This task seemed to be effective for usually well-performing students but not for the lower ability students. It appeared that more than a third of students in the class were not engaged in the task. About half the groups in the class eventually completed their movies, which was the broader inquiry task to which this task contributed. 


\subsection{Inquiry activities in the second year}

In the second year of the project, the teacher taught a class that was classified as a high performing class. He described some of their characteristics:

The second year class, as a top band class they are driven by the gathering of knowledge and recognition of their achievement. This tended to initially work against the students as they were in the mindset that they were completing the work for me and for me only. Comments such as "Is this correct?" "Have I got all the information you want?" were common. This changed as the students also changed throughout the project. The students were then able to focus on relevant themes based on what they knew, had seen, and also what they had experienced.

\subsubsection{Inquiry Activity 4: "Introduction to astronomy"}

The class began with an introduction to astronomy through a discussion of theory and some of the basis of astronomical theories (e.g., the big bang). Some videos were also used to set the scene such as a segment from the Simpsons TV program and 'Introduction to Astronomy'. Students were made aware that they were going to need to develop their own research questions as a result of their thinking about this topic. Many questions were asked during the discussion after the videos, but the teacher provided few answers. The teacher discussed around the answers, and students supplied answers to some of the questions. However, there were many questions not answered (e.g., Can we put a satellite into a black hole so we can see what's there?).

The class was divided into groups and each group initially worked on the A3 sheet 'Common ideas in Astronomy' (Table 1). Most groups were quite engaged and completed the sheet satisfactorily. 


\begin{tabular}{|l|l|l|l|l|}
\hline \multicolumn{5}{|c|}{ Common ideas in Astronomy } \\
\hline \multicolumn{1}{|c|}{ Statement following are a selection of common ideas in astronomy. Some are true and some are not. For each statement, } \\
discuss why you chose agree, disagree or don't know.
\end{tabular}

Table 1. Common ideas in Astronomy

The concept for this activity was presented to the students as 'a compare and contrast opportunity where the cultural influences of astronomy can be explored in both New Zealand and other parts of the world'. This concept was written on the white board at the front of the room in order to remind the students. The groups were given an A3 sheet and asked to develop a mind map related to astronomy. The students were experienced with the development and use of mind maps and completed this task satisfactorily (see two examples in Figure 1).There was a lot of discussion both within and between groups. Most elements of the resultant maps were technical; a few were cultural and personal. This short activity was the basis for the next activity related to constellations.
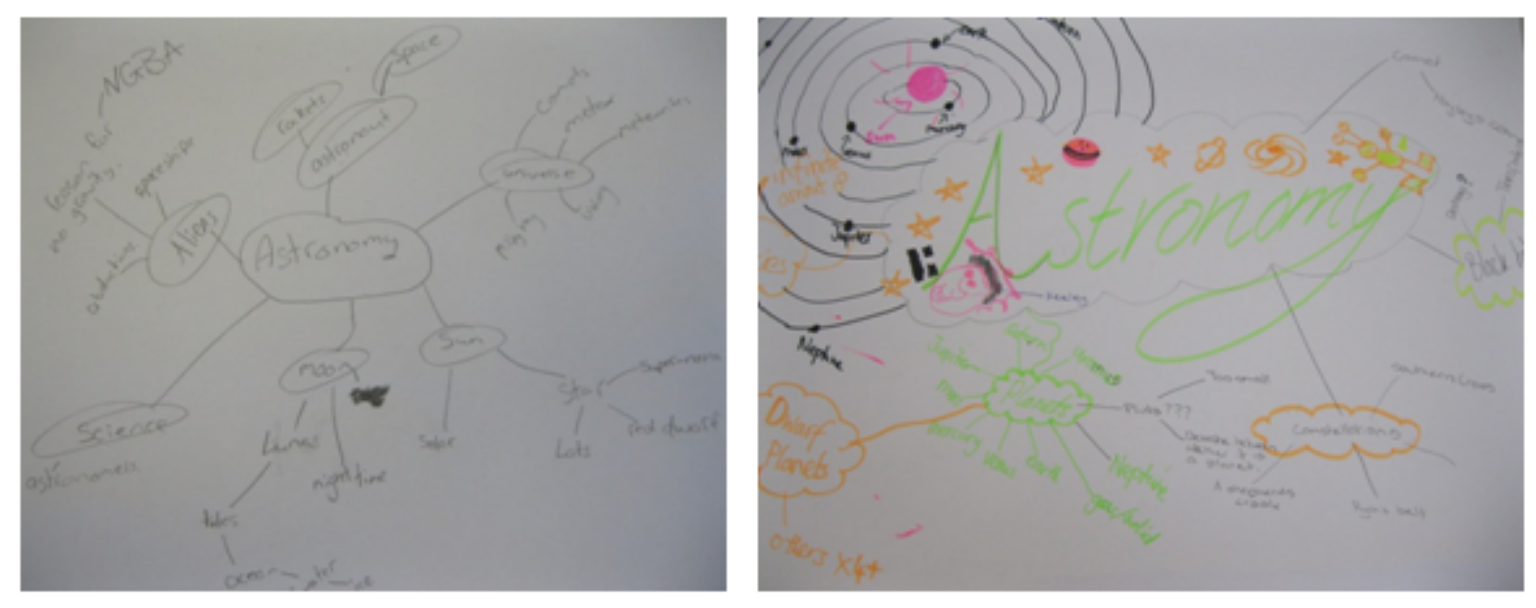

Figure 1. Students' Mind Maps 


\subsubsection{Inquiry Activity 5: "Constellations: New Zealand and Denmark"}

The teacher began the series of classes for this activity with the illustration of some free software called Stellarium, in which space can be explored from any specified location on earth in real time. The sun can be blacked out during the day to see what constellations are present. Space can be zoomed in to reveal remote bodies, and a locational grid can be revealed. For this activity, a link was made with a school in Denmark, and so the teacher showed the sky over an area of Denmark.

A new inquiry activity was introduced in this lesson, related to the cultural influences concept, focussed around 'how early cultures used stars to navigate.' Two Wallwisher Internet sites were to be used to post questions, comments and observations: one was in Denmark and the other was local. The questions were to be answered in an e-portfolio which would later be uploaded onto Moodle. The sharing of information was emphasized with the rationale of more effective learning. The students were divided into their groups and given a handout on which the task was a presentation to an astronomical society on traditional Māori astronomical knowledge from the late 1980 's.

The Wallwishersite was projected onto the whiteboard, and as students posted questions and answers on their laptop it appeared on the projected screen. This created a buzz around the class and facilitated engagement. The students also had access to the Denmark Wallwishersite, to post questions for the Denmark students or to respond to questions/comments from the Denmark students. Some students had to use Google translate to interpret the discussion from the Danish students.

One comment on the Wallwishersite was 'the average Māori knows more about the stars than the average pakeha'. The teacher used this as an opportunity to discuss the cultural context of the article, and its historical nature, recognized by a number of students who classified it as not very politically correct for current times. As their next class was not until the following week, the students were instructed to continue to use the Wallwishersite as the mechanism to ask for clarity about the task, and the teacher would check it each day. This form of out of class communication enabled the students to control their own progress to a greater degree.

The classes related to this activity began with a movie clip which was explicitly linked (by the teacher) to questions done previously on cultural aspects of astronomy. The movie clip 'The eyes of Ariki', a Māori legend related to the formation of the stars, was discussed in the context of 
the cultural interpretation of the seasons and the stars, and contrasted with the generally scientific approach taken to astronomy.

The students then moved on to answering the Astronomy questions on their task sheet. Part of the rationale for finding the answers to the questions was so the students would be able to authoritatively answer the questions that a group of preschool students were preparing for them.

\subsubsection{Inquiry Activity 6: "Explaining astronomy to pre-school students"}

\section{Preparation}

The local preschool was concurrently studying astronomy, and on a large wall board, the preschool students had been writing questions they would like to ask the secondary students. The preschool teacher then transferred their questions to Wallwisher for the secondary students to answer. The secondary teacher took a video of each student while walking around the class, which was sent to the preschool so the students there could see who they were asking their questions of.

The students worked in their groups to explore the answers to the set questions, and to prepare information to present to the preschool. They were working on the class laptops, but also using their own phones, cameras and the class flip videos to prepare their presentations. Some of the ways the groups developed their presentations included:

- Three boys made a movie, in which they were each the sun, moon and earth respectively, and spoke and moved in the movie to represent the planets.

- A mixed group developed a PowerPoint presentation which included pictures of themselves and each slide in the presentation was about an aspect of astronomy.

- Another group developed a website which had a series of questions and answers.

- A group of girls learnt 'The Planet Song' which they recorded and sent to the students.

\section{Preschool visit}

The class then visited the local preschool to make their presentations about astronomy in response to the students' questions. The preschool was about a 10 minute walk from the secondary school, so the class walked down at the end of the lunch period which led into the 
science class. The Year 9's were behaving as you would expect on their walk, being the last class on a Friday afternoon. The teacher gathered them together before entering the preschool and explained that the young children would respond to their behaviour in kind, so if they were ratty and a bit all over the place, the young children would be too.

On entering the school, the students rose to the occasion. It was organized so the secondary students rotated around the three groups of about eight preschool children in different rooms to repeat their presentations to each group. They did this in a very calm and organized way, and the pre-schoolers were very attentive.

Some students began with their prepared presentations, which varied from a song about the planets, a dynamic graphic illustrating how the sun seemed to move from morning to evening, the text of a poem one group had written, and a recording of the group explaining the sun-earthmoon relationship with the visual aids they had constructed.

Other groups communicated without the use of media. One group used balls to represent different planets and moved around to illustrate different alignments. Another had pictures of various astronomical features and talked about each one. One group were dependent on Internet access which was not available in one of the rooms, but they could not 'just talk' about it because they were dependent on the media.

The level of language was a significant element which some groups came to realize, and subsequently modified, but others pressed on regardless. It was clear which Year 9 students had younger siblings as they were able to orient their discussions to the appropriate level. Despite the fact that the teacher had spent some time discussing with the students the nature of early childhood, many groups were focussed on the development of their presentations and did not realize the significance of language level, and so began using language that was at their own level. As the teacher pointed out, a number of the students who were amongst the top in the class were unable to modify their language from that which enabled them to be top of the class: 'It was a good lesson in knowing your audience in order to effectively communicate.'

The preschool children were attentive. Some asked questions, but most left the questions to the teachers who had previously written them down.

This section has reported on the activities the teacher implemented with his students over the two year period of the study in order to provide the context for the following analysis. This 
analysis is broadly divided into student and teacher perspectives, and then the themes that arose from the interpretative approach to the analysis are elaborated.

The technological tools that were used to support inquiry learning included:

- $\quad$ Search engines (e.g., Google)

- Presentation tools (e.g., PowerPoint) and devices (e.g., flip cameras)

- Mobile devices (e.g., mobile phones, mini computers, tablets)

- Online tools (e.g.,Wallwisher, Google Docs, editable website)

- Moodle

These tools provided the students with opportunities to access resources, investigate, record evidence, present, share and discuss science ideas, and therefore provided the potential to promote students' inquiry learning.

\subsection{Student perspectives on technology-supported inquiry learning}

Data from the students(survey, observations and interviews) showed that they felt that the technological tools assisted their learning. They believed that it was easy and quick to find facts, information and answers on the Internet. For example, a student mentioned that "It helped a lot with my research, if it wasn't for Google and Office, we would be in VERY hot water."

The students found that it took them more time than they anticipated to get used to doing research, looking for information and presenting the information in their own way, and they found it both challenging and enjoyable. They also appreciated the teacher's use of technology to support presentations.

Most of the students used mobile devices (e.g., mobile phones and iPads) in the classes to access the Internet and search for information, and also to take photos and make videos. An example of the incidental use of mobile phones was when the students took photos to record the experiment they conducted in Inquiry Activity 2: "Mixtures and Compounds". The students used their recordings to review the experiment, and believed this aided their learning. They also annotated the photos and used them in their class assignment. 
Another example is the students' movie-making- short news items about the Waikato River for Māori TV. Most of the students were involved in the process of movie-making and said that they made many takes in order to produce their movies, a process which they felt helped them to shape their ideas and articulate their speeches. Students commented that "Allowing us to make videos belped our learning", and "Watching videos helped my understanding of the subject."

Collaborative online tools (e.g., Wallwisher, Google Docs and editable websites), where students could share and edit information, were considered very supportive of their science learning. For example, a student said that "Wallwisher with Denmark helped my learning" because the student 'owned' the question and the sense of immediacy related to the response was effective. Another student commented that "if one person put one answer and it wasn't quite right we could elaborate, change it slightly. We learnt from each other as we found out stuff."

The readily available technological support for collaboration, group work, discussion and communication was seen as an advantage:

Google Docs and the website enabled collaboration without being at school, it allowed my group to discuss and communicate ideas better.

The website was good to communicate through because we could ask questions and others would get back to us.

The website originally was just something fancy to develop, but it turned out that we actually used it to teach each other and learn from each other.

In inquiry activity 6, where the students were given the task of explaining astronomy to a group of preschool students, the majority of the students reported that this task helped them understand astronomy better:

Preparing for the preschool kids helped me understand the basics better because I had to make everything simple.

I had to know lots more to be able to put it in simple terms to teach.

So while the students considered that the information technology tools supported their learning, it did cause issues when technological problems occurred. 


\section{Technology and pitfalls}

The students found that the technical problems they encountered were frustrating. The school's laptops were slower than some of their personal computers, and the school's Wi-Fi network was not always accessible. It was at these times the students began using their mobile phones to access the Internet as an alternative.

A majority of the students said that they were quite comfortable with the technology, and that technology supported their learning as well as helping them understand science. However, they recognized that it was not necessarily straight forward:

Using Google to find all the answers to the questions isn't that easy, there's lots of stuff and it can be quite hard to understand and you don't always get what you are looking for. It would be good if the teacher could give us some sites that we could trust.

Some students compared this new inquiry approach to learning to the former more teacherdirected approach, and felt that their time was not as effectively used for learning. From some students' point of view, more specific guidance should have been provided by the teacher:

It took a long time to put the PowerPoint together and if we were doing things the old way we could have learnt more in that time.

At times we were kind of just given the laptops and told to go find stuff. I think for the amount of time we spent on the computers we didn't actually learn a lot. If we were given specific questions to research and study we would bave learnt quite a bit more.

\section{What the students learnt}

In the survey and interviews, the students were asked what they learnt after conducting the inquiry activities. Their feedback varied and can be categorised into two groups: science knowledge and skills.

In terms of science knowledge, the students said that they had learnt about purifying water, acids and bases, contamination, seasons, planets, gravitation, moon phases and satellites. They identified the following new skills they had developed while they were engaged in the learning tasks: problem solving, doing investigations, listening and discussing, becoming more independent in learning, collecting and collating data, computer and presentation skills. A student commented that other positive outcomes were developed during this learning process:"I went 
home and taught my dad something too, I asked him do you know how the leap years are made, he said no and I told him and I felt really smart.”

In general, from the students' perspective, technology tools which consisted of search engines, presentation tools, MS Office, Moodle, mobile devices, and collaborative editable web tools and websites assisted their learning. Although the students encountered technical problems, they believed that they learnt both new science knowledge and new skills, including science inquiry skills such as collecting, collating and analysing data, investigating and solving problems, independent research, presenting and discussing in groups. As one student commented:

I reckon we developed independent research skills because of the technology. Instead of the teacher telling us exactly what to do and what the answers were, we figured it out for ourselves.

While some students felt that this inquiry approach improved their learning, some felt it was not as efficient as the traditional teacher-directed approach which they had been used to. Consequently, there was some resistance to the student-led nature of inquiry, and some felt that they learnt more when they were told by the teacher specifically what to do.

\subsection{Teacher's perspective of technology supported inquiry learning}

The above sections present the technology-supported inquiry learning from the students' perspective. This section will discuss the same sequence of activities, but from the teacher's perspective. The teacher had little understanding of the nature of inquiry prior to this project, and developed his conceptions about inquiry at the first project workshop, and then through planning with the researchers. This developing understanding continued throughout the project as the teacher and researchers came together to share their experiences during project workshops.

In the first year, the teacher focussed on inquiry learning tasks for the students within the class. In the second year, the activities went beyond the classroom, encompassing an overseas school and a local preschool. This shift was enabled by a number of factors, as the teacher commented on the inquiry learning in the two years:

Year 1 saw some frustration, unreliable school network, equipment, and access to a school online portal such as Moodle. We re-evaluated and utilised what we had available such as phones and digital cameras. This worked well as the students were able to use an everyday item that they are familiar with and create 
and learn in their own unique way. It [the technology] allowed for reflection as they viewed their own work.

Year 2 was a higher level class where access to electronic media was pretty much the norm. Access to online resources from home was easy for this cohort, their knowledge of online applications was high, bence the development by one group of their own web site. They also worked through as a class their own Facebook page which they had set up to discuss school things. Due to the school's stance on teacher involvement on students' Facebook pages, I was not privy to these conversations. A few groups attempted to include online media with recorded media where they created short film clips to be included in a presentation.

During the two years of participating in the project, the teacher extensively scaffolded student activity. He also developed his own understandings of the nature of inquiry, and subsequently modified his pedagogical approaches. This section will examine student scaffolding and then teacher development throughout his journey.

\section{Scaffolding and student control}

For the class in the first year, the teacher felt that the students' initial interest in inquiry was low, and so paid particular attention to ensuring they were interested:

The Year 1 class, low in knowledge, ability and interest initially, by using everyday elements and themes the students were soon quick to buy in and were able to relate back to their own experiences to do with the Waikato River. This made it real and relevant.

At the beginning of the first year, when the inquiry learning was introduced to the students, significant scaffolding from the teacher was needed. The teacher initially exercised more control in the inquiry activities than he gave the students. Gradually, over the course of the year, the students took more control over their own learning. The teacher's guidance and support were gradually reduced as students' abilities progressively improved and they became more comfortable with the student-centred approach. He commented:

Significant scaffolding was required prior to any inquiry learning elements being introduced. The next stage was to allow the students an opportunity to become comfortable with the resources that we had available. This started by the use of simple recordings with their phones of tasks they undertook in class as I scaffold their learning. A learning method that allowed the students to share and replay their learning, was a concept I discovered by default but embraced as a unique learning tool. The reluctant 
students were now recording their activities, commenting on these activities and sharing their new found knowledge with others.

Normally, the school policy was that mobile phones were not allowed to be used in classes, and disciplining students for phone use had been a recurrent issue. However, due to the frustrations with the school technology systems, this rule was overridden by the teacher, which solved the technology problem, but also had the unanticipated outcome of student phone misuse not being an issue.

By initially allowing the use of phones in class, as a teacher I effectively gave them the understanding that it is Ok to use their phones to help their learning, this had a twofold effect in that classroom misuse of the phones was no longer an issue.

The students gradually felt comfortable enough with their work to show the videos that they recorded to parents and caregivers. These videos also helped the students to self-reflect when they viewed them. This provided useful scaffolding for the next inquiry theme which required the students to produce a short news item for Māori TV:

About the Waikato River for Māori TV, whilst there were very few groups that finished their movie, the preceding scaffolding of content and also the introduction of electronic devices to aid their learning was evident as they went through the process of this inquiry unit.

At the beginning of the project, the teacher had planned to utilize the school systems to their fullest extent, however, he had not used them extensively in his class before, and this intent required modification in the face of the reality of the systems.

At the time of starting [Name of the School] had grand ideas of implementing Moodle as a learning tool, many promises were made as to when things would be available. The initial thinking was to create an online learning environment for interaction with each other. Sadly this did not happen and this elearning tool did not eventuate.

The teacher had developed his concepts of the nature of inquiry learning in year one of the project, realizing that a focus on a particular aspect of inquiry was appropriate in building up student skills to the point where they could engage in more independent and comprehensive inquiry activities. This approach was the result of both the student ability level and the teacher's still developing confidence with the inquiry approach. The focus of year two, according to the teacher, was the sharing information aspect of inquiry, for example through working with the 
school in Denmark (Inquiry activity 5). Even with the more capable students of year two, the teacher realized that significant teacher support was required.

The focus on sharing of information meant working with a school overseas, in a different time zone which created a few issues, as a teacher there was significant input by me to develop and implement information sharing possibilities. Whist the students enjoyed this opportunity to share, the time difference did create a lag in communication where the technology allowed for instantaneous responses but time zones didn't. This led me onto developing our own class Wallwisher whereby projecting onto the whiteboard during class allowed an instantaneous response to any questions and comments, almost competitive as the students strived to prove each other wrong.

The teacher recognized the importance of understanding the audience in the sharing of inquiry outcomes. For this reason he incorporated the task explaining aspects of astronomy to smaller children (Inquiry activity 6). The teacher elaborated on the reason underpinning this task:

An important element of inquiry is that to be successful an audience for the work is required, on the completion of the school year in Denmark, [name of the preschool], a local preschool was chosen as our next audience. Reason being was that to fully understand the knowledge they had derived from their initial sharing of information, they would now need to deliver in a manner that a much younger audience would understand. This was a task that all students struggled with as the level of their knowledge had to be simplified for the younger kids. Also the method of delivery, in particular electronic media, whilst wonderful and informative to their peers, is somewhat different to a different audience.

Although the students took significant control of their learning, scaffolding was still needed:

The class was fully aware of the inquiry task at hand and constant reminders of the need to consider the audience was a repeated theme, a need to fully understand their content so that they were the expert and able to explain at an appropriate level. Advice that was not heeded by some, as they tended to work at a much higher level than their audience, and struggled with the presentations they had developed.

The teacher noted that his main role during the actual inquiry tasks was a departure from his usual pedagogical approaches which were more directive, in that he acted as a facilitator who monitored and guided each group through their learning. This. Most of the student groups effectively allocated tasks to each member, and so developed the roles of experts amongst their peers. 


\section{Learning about inquiry teaching}

At the beginning of the first year of the project, the teacher said that he was struggling with his teaching. After two years involvement in the project, the teacher reflected on his experience in the first year:

It was a real learning year for both students and teacher, they learnt content and the possible use of electronic devices and as a teacher I became a lot more aware of the benefit of allowing students to learn both individually and collectively in an environment that they were very familiar with.

It wasn't only the students who had difficulty adapting to an inquiry approach. While the students found the lack of teacher direction initially disconcerting, the teacher also found the need to pass control of learning to the students difficult.

In Year 1, as a teacher the initial letting go of the control of the students learning was the biggest burdle. This was overcome by the initial planning and brainstorming with the research team that set the context and direction of the inquiry. From developing an understanding of the students over time, I was able to identify the level of input required and structure any scaffolding opportunities accordingly.

The biggest element I learnt was, in fact, a reminder of the varied abilities of each student in class. With this also came the reluctance to relinquish control of the students' learning. A big step.

The teacher pointed out that the key things he learned during the two years that contributed to successful inquiry learning included:

- Establishing an end goal for each working group, and setting group tasks so they are achievable but also so that they extend the learning;

- Allowing groups to work at their own speed, letting them establish their own milestones and time lines to reach their goals;

- The teacher's role is a facilitator who monitors and guides groups through their learning during the actual inquiry.

- Adapting an approach which is dependent on an understanding of the students' focus/experiences/ attitudes and abilities. 


\section{Discussion and conclusion}

There was one overarching theme with four key elements that emerged from the analysis of the data related to this case study. It seems that a key requirement in using information technology to support inquiry learning is flexibility: to plan for inquiry considering the context, to seek alternatives when the technology does not work, to change notions of what scaffolding (both conceptual and procedural) might be necessary to ensure success, and to have dispersed notions of who is the expert. The discussion of the conclusions of this case will be structured around these elements of flexibility in:

- the nature of inquiry,

- the use of technology,

- scaffolding of students,

- $\quad$ sources of expertise.

\subsection{The nature of inquiry}

There are many approaches to inquiry learning (Crawford, 2007), and the nature of inquiry (particularly more open inquiry) can seem ill-defined and hard to guide and manage, especially when it is new for teachers and students (Rodriguez-Arteche \& Martinex-Aznar, 2016). The teacher in this project began his inquiry projects in ways he felt comfortable, and to the extent he felt his students could achieve. This approach resulted in the teacher focussing on particular aspects of inquiry learning skills, with the notion that a repertoire of skills would be developed over time to the point where students were individually and collectively capable of engaging with significant science inquiry.

By taking these small forays into parts of a focused inquiry cycle and progressively building on student experiences, the teacher and his students developed a better understanding, as well as the confidence and capacity, to conduct inquiries supported by information technology tools.

The teacher benefitted from opportunities to reflect individually and with peers as a means of enhancing his confidence and informing the refinement of his information technologysupported inquiry practices. These discussions at the workshops and meetings with the researchers enabled him to share ideas and to benefit from their research, confirming research 
that indicates teachers need time and support in order to develop skills and beliefs (Lee et al, 2010).

\subsection{The use of technology}

There was a need for flexibility by the teacher in this project in response to a range of technological issues. Slow, malfunctioning or unavailable service and technologies were a source of frustration for both students and teacher. There were a number of instances where the teacher and students used their own equipment such as iPhones, iPads, and digital cameras to circumvent infrastructure challenges and facilitate their inquiries.

It was also clear that there was value in students being able to draw from a range of technologies to undertake the different aspects of science inquiry learning. Tools that allowed students to simulate or undertake scientific processes such as observing and reviewing, and that enabled the multimodal expression of emerging ideas were particularly advantageous. The findings illustrate the value of student access to a range of information technology tools in enabling students to recognize the value of using technologies to undertake scientific investigations (Kukkonen, Dillon, Kärkkäinen, Hartikainen-Ahia \& Keinonen, 2016).

It was observed that when students have a range of information technologies available to them, they develop discernment in the selection of tools that best enable them to achieve their goals related to the different aspects of inquiry. They develop a pragmatism in the use of what works best for them, and as a result of this effective decision making they assume more ownership of their learning.

Just as research has indicated that technologies can support inquiry learning (Bolstad et al, 2012), these findings indicate that teacher inquiry practices can, conversely, be hindered by a lack of technological access or by technical failure. More robust networking platforms (stable access to the Internet) are required to overcome this challenge. School policies that affirm productive information technology tool use, for example, free access to the Internet and student smart phone use, facilitate teachers and students taking up and incorporating these tools in their teaching and learning. 


\subsection{Scaffolding of students}

When students were expected to adapt to a situation where they have considerable freedom to think and investigate, this was disconcerting for them and they were left unsure about what they had to do and what they had learned. The freedom to make decisions was daunting as well as a source of confusion or frustration with both teacher and students. As Hoffman et al., (2003) and Lehtinen and Viiri (2016) indicate the learning support provided by the teacher is essential to improve learning.

Introducing short and focused episodes of inquiry over time, and scaffolding the development of new skills was found to be effective in helping students to become comfortable with this approach. This concurs with Bell et al.'s (2005) view that students should progress gradually to higher levels of inquiry supported by appropriate scaffolding. As this approach was new for the teacher also, flexibility in the form of trial and error, related to both skills and knowledge, was necessary to get it right (Goldman, Pea, Barron \& Derry, 2007).

It was also clear in this project that the ability of the students was a determining factor in the nature of the scaffolding needed to support an inquiry approach. The lower ability class in the first year necessitated more scaffolding than did the higher ability class in the second year.

The skills necessary for students to engage in information technology-supported inquiry learning are also necessary to scaffold (Wright, 2010; Anderson, 2014), but examples of successful pedagogical strategies and activities are lacking (Wallace et al., 2000). In this study, short inquiry episodes were needed at times to develop student technological skills, the skills needed to work collaboratively and even self-management skills. A series of focused episodes was found to support students in learning to value the different ways information technologies can enhance inquiry learning.

\subsection{Sources of expertise}

The traditional model of teacher as expert was inappropriate in this technology-supported inquiry classroom, in which expertise was distributed in many ways. For example, the funds of knowledge the students bring to the classroom was recognized as a valuable resource in progressing science inquiries. The students naturally came to recognize that the teacher is not necessarily the source of all knowledge. Student ownership of and control over the available 
technologies meant they could use them in their science inquiries as and when required, reducing their need to rely on the teacher or on school managed systems.

Over time, and with increasing knowledge, experience and confidence the teacher came to encourage students to explore and share with the class community the different opportunities for investigation that different tools afford. The teacher developed an understanding of student technological capabilities and the nature of tools that students own and can bring to class, and then utilised this information to build the different affordances into future class inquiry episodes.

So, flexibility in traditional teacher and student roles was required to take advantage of the possibilities information technology tools offer for collaboration and the discussion and exploration of the various aspects of science inquiry. The range of possibilities also points to the need for teachers to facilitate students' confidence and capacity to access and discern between a wide range of resources within and beyond the class community (Chu \& Sung, 2016). Students also need to recognize and be empowered to undertake more ownership and responsibility for their own learning in the inquiry process. The teacher developed his own and his students' capacity and confidence to undertake short and focused inquiry episodes and then built on these experiences.

Making accessible broader contexts for both sources of expertise and sharing of findings has been recognized as an affordance of the use of information technologies (Erstad, 2005; Wright, 2010). It was the case in this project that hitherto unavailable sources of expertise, and new opportunities for sharing findings were facilitated by the use of information technologies, which also appeared to enhance student engagement and learning

The findings from this case study indicate that information technology can be a powerful tool to support inquiry teaching. The possible implications derived from this research are that:

- Teachers need time to plan for inquiry learning, and through planning and implementing small steps at a time, develop confidence to progress further.

- Students also need to be gently introduced to an inquiry approach, if their prior experience has been with teacher directed pedagogies.

- Students are a resource that teachers can incorporate into their learning plans, at times in terms of content, but as was particularly evident in this research, also for technologies. 
- A range of networked technology tools must be available to students in order to provide all the affordances required for an effective inquiry approach.

\section{Acknowledgements}

This article is derived from a research project titled Networked Inquiry Learning in Secondary Science classrooms (NILSS) which was funded by the Teaching and Learning Research Initiative (TLRI) and was reported at: http://www.tlri.org.nz/sites/default/files/projects/9291 summaryreport.pdf). The project was led by Kathrin Otrel-Cass and John Williams. The research team included Bronwen Cowie, Kathy Saunders, Simon Taylor, Nhung Nguyen, Suskia van der Merwe, Alison Basel and Jenny Mangan.

\section{References}

Anderson, K. (2014) IScience: A computer-supported collaborative inquiry learning project for science students in secondary and tertiary science education. International Journal of Innovation in Science and Mathematics Education, 22(1), 14-31

Bell, R.L., Smetana, L., \& Binns, I. (2005). Simplifying inquiry instruction. The Science Teacher, 72(7), 30-33.

Bolstad, R., \& Hipkins, R. (2008). Seeing yourself in science. Wellington. New Zealand: New Zealand Council For Educational Research. Available online at: http://www.nzcer.org.nz/system/files/16626.pdf

Bolstad, R., Gilbert, J., McDowall, S., Bull, A., Boyd, S., \& Hipkins, R. (2012). Supporting futureoriented learning \& teaching: A New Zealand perspective. Wellington, New Zealand: Ministry of Education. Available online at: http://westernsprings.school.nz/New \%20School/becoming a new school/Resources/Bolstad Gilbert FutureOriented.pdf

Chu, H., \& Sung, Y. (2016). A context-aware progressive inquiry-based augmented reality system to improving students' investigation learning abilities for high school geography courses. Proceedings - 2016 5th ILAI International Congress on Advanced Applied Informatics, 353-356. https://doi.org/10.1109/IIAI-AAI.2016.112

Cowie, B., Jones, A., Harlow, A., McGee, C., Cooper, B., Forret, M.at al. (2007). TELA: Laptops for teachers evaluation final report year 9-13. Hamilton, New Zealand: University of Waikato. 
Cowie, B., Moreland, J., \& Otrel-Cass, K. (2013). Expanding notions of assessment for learning: Inside science and technology primary classrooms. Rotterdam/Boston/Taipei: Sense Publishers. https://doi.org/10.1007/978-94-6209-061-3

Crawford, B.A. (2000). Embracing the essence of inquiry: New roles for science teachers. Journal of Research in Science Teaching, 37(9), 916-937. https://doi.org/10.1002/1098-2736(200011)37:9<916::AIDTEA4>3.0.CO;2-2

Crawford, B.A. (2007). Learning to teach science as inquiry in the rough and tumble of practice. Journal of Research in Science Teaching, 44(4), 613-642. https://doi.org/10.1002/tea.20157

Erstad, O. (2005). Expanding possibilities: Project work using ICT. Human Technology, 1(2), 216-245. https://doi.org/10.17011/ht/urn.2005359

Feldman, A., Konold, C., Coulter, B., Conroy, B., Hutchison, C., \& London, N. (2000). Network science, a decade later: The Internet and classroom learning. Mahwah, NJ: Lawrence Erlbaum Associates.

Gengarelly, L.M., \& Abrams, E.D. (2008). Closing the gap: Inquiry in research and the secondary science classroom. Journal of Science Education and Technology, 18(1), 74-84.

https://doi.org/10.1007/s10956-008-9134-2

Goldman, R., Pea, R., Barron, B., \& Derry, S.J. (2007). Video research in the learning sciences. Mahwah, NJ: Lawrence Erlbaum Associates.

Guba, E., \& Lincoln, Y. (1994). Competing paradigms in qualitative research. In Handbook of qualitative research (pp. 105-117). Thousand Oaks, CA: Sage. Available online at: http://us.share.geocities.com/dian marie hosking/PdfFiles/GubaLincoln.pdf

Haug, B. (2014) Inquiry based science: Turning teachable moments into learnable moments. Journal of Science Teacher Education, 25(1), 79-96. V

Hong, J., Hwang, M., Lui, M., Ho, H. \& Chen, Y. (2014). Using a "prediction-observationexplanation" inquiry model to enhance student interest and intention to continue science learning predicted by their Internet cognitive failure. Computers in Education, 72, 110-120. https://doi.org/10.1016/j.compedu.2013.10.004

Hoffman, J.L., Wu, H.-K., Krajcik, J.S., \& Soloway, E. (2003). The nature of middle school learners' science content understandings with the use of on-line resources. Journal of Research in Science Teaching, 40(3), 323-346. https://doi.org/10.1002/tea.10079 
Kukkonen, L., Dillon, P., Kärkkäinen, S. Hartikainen-Ahia, A., \& Keinonen, T. (2016). Preservice teachers' experiences of scaffolded learning in science through a computer supported collaborative inquiry. Education and Information Technologies, 21(2), 349-371.

https://doi.org/10.1007/s10639-014-9326-8

Lee, H.-S., Linn, M.C., Varma, K., \& Liu, O.L. (2010). How do technology-enhanced inquiry science units impact classroom learning?. Journal of Research in Science Teaching, 47(1), 71-90. https://doi.org/10.1002/tea.20304

Lehtinen, A., \& Viiri, A. (2016). Guidance Provided by Teacher and Simulation for Inquiry-Based Learning: A Case Study. Journal of science education and technology. In press, 1-14.

https://doi.org/10.1007/s10956-016-9672-y

Merriam, S.B. (2002). Qualitative research in practice: Examples for discussion and analysis. San Francisco, CA: Jossey-Bass.

Ministry of Education (2006). Enabling the 21st century learner: An e-learning action plan for schools, 2006-2010. Wellington, New Zealand: Learning Media.

National Research Council (2000). Inquiry and the National Science Education Standards: A guide to teaching and learning. Washington, DC: The National Academy Press.

Otrel-Cass, K., Cowie, B., \& Khoo, E. (2011). Augmenting primary teaching and learning science through ICT. Summary Report. Wellington: Teaching Learning Research Initiative. Available online at: http://www.tlri.org.nz/sites/default/files/projects/9271 otrel-cass-summaryreport.pdf

Rodriguez-Arteche, I., \& Martinex-Aznar, M. (2016). Introducing Inquiry-Based Methodologies during Initial Secondary Education Teacher Training Using an Open-Ended Problem about Chemical Change. Journal of Chemical Education, 93(9), 1528-1535.

https://doi.org/10.1021/acs.jchemed.5b01037

Schwartz, R.S., Lederman, N.G., \& Crawford, B.A. (2004). Developing views of nature of science in an authentic context: An explicit approach to bridging the gap between nature of science and scientific inquiry. Science Education, 88(4), 610-645. https://doi.org/10.1002/sce.10128

Tseng, C.-H., Tuan, H.-L., \& Chin, C.-C. (2012). How to help teachers develop inquiry teaching: Perspectives from experienced science teachers. Research in Science Education, 43(2), 809-825. https://doi.org/10.1007/s11165-012-9292-3 
Tytler, R., Osborne, J., Williams, G., Tytler, K., \& Cripps Clark, J. (2008). Opening up pathways: Engagement in STEM across the Primary-Secondary school transition. Department of Education, Employment and Workplace Relations. Available online at: http://www.industry.gov.au/skills/Resources/Documents/OpenPathinSciTechMathEnginPrimSecSchTrans.pdf

Voogt, J., Erstad, O., Dede, C., \& Mishra, P. (2013). Challenges to learning and schooling in the digital networked world of the 21st century. Journal of Computer Assisted Learning, 29(5), 403-413. https://doi.org/10.1111/jcal.12029

Wallace, C.S., \& Kang, N.H. (2004). An investigation of experienced secondary science teachers' beliefs about inquiry: An examination of competing belief sets. Journal of Research in Science Teaching, 41(9), 936-960. https://doi.org/10.1002/tea.20032

Wallace, R.M., Kupperman, J., Krajcik, J., \& Soloway, E. (2000). Science on the web: Students online in a sixth-grade classroom. Journal of the Learning Sciences, 9(1), 75-104. https://doi.org/10.1207/s15327809jls0901_5

Williams, J., Cowie, B., Khoo, E., Saunders, K., Taylor, S., \& Otrel-Cass, K. (2013). Networked inquiry learning in secondary science classrooms. New Zealand Council of Educational Research. Available online at: http://www.tlri.org.nz/sites/default/files/projects/9291 summaryreport.pdf

Windschitl, M. (2003). Inquiry projects in science teacher education: What can investigative experiences reveal about teacher thinking and eventual classroom practice?. Science Education, 87(1), 112-143. https://doi.org/10.1002/sce.10044

Wright, N. (2010). e-Learning and implications for New Zealand schools: A literature review. Ministry of Education. Available online at:

http://edcounts.squiz.net.nz/ data/assets/pdf file/0006/77667/948 ELearnLitReview.pdf

Published by OmniaScience (www.omniascience.com)

Journal of Technology and Science Education, 2017 (www.jotse.org)

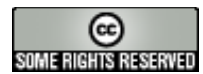

Article's contents are provided on an Attribution-Non Commercial 3.0 Creative commons license. Readers are allowed to copy, distribute and communicate article's contents, provided the author's and JOTSE journal's names are included. It must not be used for commercial purposes. To see the complete licence contents, please visit http://creativecommons.org/licenses/by-nc/3.0/es/ 